\title{
Inhibition of the $\alpha$-Subunit of Phosphoinositide 3-Kinase in Heart Increases Late Sodium Current and Is Arrhythmogenic ${ }^{\text {[ }}$
}

\author{
Tao Yang, David F. Meoli, Javid Moslehi, and Dan M. Roden \\ Departments of Medicine (T.Y., D.F.M, J.M., D.M.R.), Pharmacology (T.Y., D.M.R.), and Biomedical Informatics (D.M.R.), \\ Vanderbilt University School of Medicine, Nashville, Tennessee
}

Received November 2, 2017; accepted February 28, 2018

\begin{abstract}
Although inhibition of phosphoinositide 3-kinase (PI3K) is an emerging strategy in cancer therapy, we and others have reported that this action can also contribute to drug-induced QT prolongation and arrhythmias by increasing cardiac late sodium current $\left(I_{\mathrm{NaL}}\right)$. Previous studies in mice implicate the $\mathrm{PI} 3 \mathrm{~K}-\alpha$ isoform in arrhythmia susceptibility. Here, we have determined the effects of new anticancer drugs targeting specific PI3K isoforms on $\mathrm{I}_{\mathrm{NaL}}$ and action potentials (APs) in mouse cardiomyocytes and Chinese hamster ovary cells $(\mathrm{CHO})$. Chronic exposure (10-100 nM; 5-48 hours) to PI3K- $\alpha$-specific subunit inhibitors BYL710 (alpelisib) and A66 and a pan-PI3K inhibitor (BKM120) increased $I_{\mathrm{NaL}}$ in SCN5A-transfected $\mathrm{CHO}$
\end{abstract}

cells and mouse cardiomyocytes. The specific inhibitors (10-100 $\mathrm{nM}$ for 5 hours) markedly prolonged APs and generated triggered activity in mouse cardiomyocytes (9/12) but not in controls (0/6), and BKM120 caused similar effects (3/6). The inclusion of watersoluble PIP3, a downstream effector of the PI3K signaling pathway, in the pipette solution reversed these arrhythmogenic effects. By contrast, inhibition of PI3K- $\beta,-\gamma$, and $-\delta$ isoforms did not alter $\mathrm{I}_{\mathrm{NaL}}$ or APs. We conclude that inhibition of cardiac PI3K$\alpha$ is arrhythmogenic by increasing $I_{\mathrm{NaL}}$ and this effect is not seen with inhibition of other PI3K isoforms. These results highlight a mechanism underlying potential cardiotoxicity of PI3K- $\alpha$ inhibitors.

\section{Introduction}

Intracellular phosphoinositide 3-kinase (PI3K) is a large heterodimeric protein consisting of a $110-\mathrm{kDa}$ catalytic subunit $(\mathrm{p} 110 \alpha, \mathrm{p} 110 \beta, \mathrm{p} 110 \delta$, or $\mathrm{p} 110 \gamma)$ that confers enzyme activity and a regulatory subunit (Damilano et al., 2010). A major product of PI3K activation is the effector phosphatidylinositol-3,4,5-trisphosphate (PIP3). The PI3K pathway is critical for cell survival and growth, and can be activated by growth factors binding to cell-surface receptors (Berenjeno and Vanhaesebroeck, 2009). Activated PI3K signaling is a frequent feature in cancer (Chen et al., 2012), and can lead to abnormal cell growth, uncontrolled cell proliferation, increased cell survival, and enhanced cancer cell motility. Therefore, the PI3K pathway is increasingly targeted in human cancers (Agarwal et al., 2010; Courtney et al., 2010; LoRusso, 2016).

In heart, activation of the PI3K-PIP3 pathway has been associated with cardiac hypertrophic growth (Shioi et al., 2000; Matsui et al., 2003; Rigor et al., 2009), and more recently

This work was supported by the National Institutes of Health (Grants GM115305, HL118952).

https://doi.org/10.1124/jpet.117.246157.

S This article has supplemental material available at jpet.aspetjournals.org. with arrhythmias. Pretorius et al. (2009) reported that mice with dilated cardiomyopathy crossed with mice expressing a dominant negative PI3K- $\alpha$ construct displayed increased atrial fibrillation $(\mathrm{AF})$, and in human subjects with $\mathrm{AF}$, PI3K atrial activity was reduced compared with that in patients with normal rhythm. Lu et al. (2012) first reported a role for the PI3K-PIP3 signaling pathway in arrhythmias related to abnormal ventricular repolarization in their studies of the tyrosine kinase inhibitor nilotinib, used to treat chronic myelogenous leukemia. The nilotinib label warns that the drug prolongs the QT interval and can thereby cause the polymorphic ventricular tachycardia torsades de pointes. $\mathrm{Lu}$ et al. showed that whereas action potential duration (APD, a cellular surrogate for QT interval) in canine cardiac myocytes acutely exposed to nilotinib was unchanged, chronic (hours) exposure prolonged APD, and the major effect was to enhance "late" (noninactivating) sodium current $\left(\mathrm{I}_{\mathrm{NaL}}\right)$, an effect well known to prolong QT and cause arrhythmias (Antzelevitch et al., 2014; Belardinelli et al., 2015). There was also modest reduction in the rapidly activating delayed rectifier potassium current $\mathrm{I}_{\mathrm{Kr}}$ and the slowly activating delayed rectifier potassium current $\mathrm{I}_{\mathrm{Ks}}$, attributed to decreased cell surface expression. Subsequently, we showed (Yang et al., 2014) that multiple antiarrhythmic and other drugs thought to prolong QT interval by blocking $\mathrm{I}_{\mathrm{Kr}}$ also increased $\mathrm{I}_{\mathrm{NaL}}$ during chronic

ABBREVIATIONS: AP, action potential; APD, action potential duration; $\mathrm{APD} \mathrm{Do}_{9}$, action potential duration at $90 \%$ repolarization; $\mathrm{CHO}$, Chinese hamster ovary; EADs, early afterdepolarizations; DAD, delayed afterdepolarizations; HERG, older terminology for $K C N H 2$; $I_{\mathrm{NaL}}$, late sodium current; $\mathrm{I}_{\mathrm{TO}}$, transient outward potassium current; $\mathrm{I}_{\mathrm{Kr}}$, the rapidly activating delayed rectifier potassium current; $\mathrm{I}_{\mathrm{Ks}}$, the slowly activating delayed rectifier potassium current; $K C N E 1$, gene encoding an $I_{K s}$ function modifying subunit; $K C N E 2$, gene encoding an $I_{K r}$ function modifying subunit; $K C N H 2$, gene encoding the $\mathrm{I}_{\mathrm{Kr}}$ channel; $K C N Q 1$, gene encoding the $\mathrm{I}_{\mathrm{Ks}}$ channel; $\mathrm{Na}_{\mathrm{v}} 1.5$, cardiac sodium channel protein; NMDG, $N$-methyl-D-glucamine; PI3K, phosphoinositide 3-kinase; PIP3, phosphatidylinositol (3,4,5)-trisphosphate; SCN5A, cardiac sodium channel gene. 
(hours-long) exposure and were arrhythmogenic in cardiomyocytes from adult mice, which lack $\mathrm{I}_{\mathrm{Kr}}$ and $\mathrm{I}_{\mathrm{Ks}}$. This effect was blocked by including PIP3 in the patch pipette and was most prominent with drugs thought to be highly arrhythmogenic like dofetilide, which produces long QT related arrhythmias in $>1 \%$ of treated patients (Abraham et al., 2015), and much less prominent or absent with QT-prolonging drugs like moxifloxacin or thioridazine that cause arrhythmias much more rarely. In that study, we also showed that dofetilide inhibited the phosphorylation of Akt, a downstream target of PI3K, whereas moxifloxacin did not (Yang et al., 2014). QT intervals are prolonged in diabetes, and Lu et al. (2013) have shown AP prolongation owing to increased $\mathrm{I}_{\mathrm{NaL}}$ in myocytes from mice models of diabetes.

The identification of PI3K as a target in cancer has led to the development of isoform-specific inhibitors. In this study, we used these reagents to identify the specific arrhythmogenic pathway in vitro. These findings not only dissect a novel arrhythmogenic pathway in drug-induced arrhythmias and possibly other clinical settings but also have implications for development and use of PI3K inhibitors in cancer (Yap et al., 2015; Massacesi et al., 2016).

\section{Materials and Methods}

Isolation of Mouse Ventricular Cardiomyocytes. Given the recognition of a gender effect on repolarization in mice (Lowe et al., 2012), these experiments were conducted in isolated ventricular myocytes from adult female C57 mice (three hearts in each group, two to three cells from each heart). Ventricular myocytes were isolated by a modified collagenase/protease method, as previously reported (Yang et al., 2012, 2014). In this study, at least three mouse hearts were isolated for collection of electrophysiological data for each study group. All procedures were approved by the Institutional Animal Care and Use Committee at Vanderbilt University.

FuGENE6-Mediated Ion Channel Expression and Chinese Hamster Ovary Cell Transfection. In Chinese hamster ovary (CHO) cells, transient transfections were performed as previously reported (Yang et al., 2012) to express cardiac ion channels: $2 \mu \mathrm{g}$ of the cDNA encoding human SCN5A (encoding the cardiac sodium channel) or KCNH2 (HERG) + KCNE2 (Mirp1) (encoding $\left.\mathrm{I}_{\mathrm{Kr}}\right), K C N Q 1+K C N E 1$ (encoding $\mathrm{I}_{\mathrm{Ks}}$ ), CACNA1C+CACNB2 (encoding the L-type calcium channel), and $0.5 \mu \mathrm{g}$ of a plasmid for green fluorescent protein (as a marker to identify successfully transfected cells for subsequent patch clamp experiments) were mixed with $10 \mu \mathrm{l}$ of FuGENE6 (Roche, Basel, Switzerland) in $0.5 \mathrm{ml}$ serum-free Dulbecco's modified Eagle's medium and incubated for 30 minutes, after which the standard medium was replaced for a 48-hour incubation. The cells were harvested by brief trypsinization and stored in standard medium for use within 10 hours. Electrophysiological data in CHO cells were collected from 2-3 separate cell transfections in each experimental group.

Late Sodium Current Recording. Endogenous late sodium current $\left(\mathrm{I}_{\mathrm{NaL}}\right)$ in cardiac cells is very small $(\sim 0.5 \%$ of peak sodium current, with a physiologic concentration of extracellular sodium) (Saint et al., 1992; Ju et al., 1994). We used previously described methods (Yang et al., 2012, 2014) to record $\mathrm{I}_{\mathrm{NaL}}$ in whole-cell voltage clamp mode at room temperature $\left(22-23^{\circ} \mathrm{C}\right)$. To optimize $\mathrm{I}_{\mathrm{NaL}}$ recordings in mouse ventricular myocytes, the external bath solution was $\mathrm{K}^{+}$- and $\mathrm{Ca}^{2+}$-free and contained (in millimolar concentrations) $\mathrm{NaCl} 135, \mathrm{MgCl}_{2}$ 1.0, glucose 10, and HEPES 10; the $\mathrm{pH}$ was 7.4, adjusted with $\mathrm{CsOH}$. To rule out the possibility that during the test pulse the large rapid sodium current in mouse ventricular myocytes could be out of voltage clamp control and alter the measurement of $\mathrm{I}_{\mathrm{NaL}}$, in some experiments we lowered the external sodium concentration to $50 \mathrm{mmol} / \mathrm{l}$ to better control peak $\mathrm{I}_{\mathrm{Na}}$ and used NMDG to replace $85 \mathrm{mM}$ sodium in the above solution. In SCN5A-transfected
CHO cells, peak and late sodium currents were recorded with external Tyrode's solution (in millimoles per liter): $\mathrm{NaCl} 135, \mathrm{CalCl}_{2} 1.8, \mathrm{KCl}$ $4.0, \mathrm{MgCl}_{2}$ 1.0, HEPES 5, glucose 10, with a $\mathrm{pH}$ of 7.35 (adjusted by $\mathrm{NaOH}$ ). The pipette (intracellular) solution contained (in millimoles per liter, NaF 5, CsF 110, CsCl 20, EGTA 10, and HEPES 10; the pH was 7.4, adjusted with $\mathrm{CsOH}$. To eliminate possible L-/T-type inward calcium currents and transient outward potassium current $\left(\mathrm{I}_{\mathrm{TO}}\right)$ in mouse ventricular myocytes, nisoldipine $(1 \mu \mathrm{M}), \mathrm{NiCl}_{2}(200 \mu \mathrm{M})$, and 4-aminopyride $(500 \mu \mathrm{M})$ were added into the bath solution.

Because previous studies (Lu et al., 2012; Yang et al., 2014; Qiu et al., 2016) have demonstrated that hours of drug exposure are required to demonstrate increased $\mathrm{I}_{\mathrm{NaL}}$, data were collected after acute ( 10 minutes) and chronic (5-48 hours) exposures. To record $\mathrm{I}_{\mathrm{NaL}}$, we used a 200-millisecond voltage clamp protocol, from the holding potential of $-120 \mathrm{mV}$ to a test potential to $-30 \mathrm{mV}$. $\mathrm{I}_{\mathrm{NaL}}$ was measured in a 3-millisecond time window before the capacity transient, 195-198 milliseconds after the start of the pulse, and expressed as the percentage of peak sodium current.

Action Potential Recordings. In current-clamp mode, action potentials (Aps) from isolated mouse ventricular myocytes were elicited by injection of a brief stimulus current (1-2 nA, 2-6 milliseconds) at stimulation rates of $1 \mathrm{~Hz}$ and $0.1 \mathrm{~Hz}$. For AP experiments, the bath (extracellular) solution was normal Tyrode's, containing (in millimoles per liter): $\mathrm{NaCl} 135, \mathrm{KCl} 4.0, \mathrm{CaCl}_{2} 1.8$, and $\mathrm{MgCl}_{2}$ 1.0, HEPES 5.0, glucose 10, with a $\mathrm{pH}$ of 7.4. The pipette-filling (intracellular) solution contained (in millimoles per liter): $\mathrm{KCl} \mathrm{130,}$ ATP- $\mathrm{K}_{2} 5.0, \mathrm{MgCl}_{2} 1.0, \mathrm{CaCl}_{2}, 1.0$, BAPTA 0.1 , and HEPES 5.0, with a $\mathrm{pH}$ of 7.3 (adjusted by $\mathrm{KOH}$ ). Ten successive AP traces elicited with a stimulation rate of $1 \mathrm{~Hz}$ were averaged for analysis of action potential durations at $90 \%$ repolarization $\left(\mathrm{APD}_{90}\right)$. Under chronic (5 hours) exposure to PI3K inhibitors, abnormal APs were defined as those with early afterdepolarizations (EADs), delayed afterdepolarizations (DADs), or triggered activity at a slow stimulation rate $(0.1 \mathrm{~Hz})$, which enhances late sodium current (Wu et al., 2011).

For the experiments to observe the effect of intracellular PIP3, water-soluble PIP3 $(1 \mu \mathrm{M})$ was added to the pipette (intracellular) solution. Data were continuously collected at $0.1 \mathrm{~Hz}$ for $3-5$ minutes.

Recording of Cardiac Potassium and L-Type Calcium Currents. To determine whether PI3K inhibition influences other cardiac repolarizing potassium currents (such as KCNH2-encoded $\mathrm{I}_{\mathrm{Kr}}$ or the transient outward current $\mathrm{I}_{\mathrm{TO}}$ ), $\mathrm{KCNH} 2$-transfected $\mathrm{CHO}$ cells (for $\mathrm{I}_{\mathrm{Kr}}$ ) and adult mouse cardiomyocytes (for $\mathrm{I}_{\mathrm{TO}}$ ) were exposed to PI3K- $\alpha$ inhibitors acutely and chronically. Experiments were also conducted in transfected $\mathrm{CHO}$ cells as above. The drug concentrations and voltage clamp protocols used are shown in the figures. All electrophysiological data were analyzed using pCLAMP version 9.2 software and the figures were prepared by using Origin 8.5.1 software (OriginLab Corp., Northampton, MA).

Glass microelectrodes were heat-polished to tip resistances of 2-3 M $\Omega$. Data acquisition was carried out using an Axopatch 200B patch-clamp amplifier and pCLAMP version 9.2 software (MDS Inc., Mississauga, Ontario, Canada). Currents were filtered at $100 \mathrm{kHz}$ ( $-3 \mathrm{~dB}$, four-pole Bessel filter) and digitized using an analog-to-digital interface (DigiData 1322A; MDS Inc.). To minimize capacitive transients, capacitance and series resistance were corrected $\sim 80 \%$. Cell size (in picofarad) was calculated by Membrane Test (OUT 0) in pClamp 9.2. Clamp protocols used are shown on the figures.

Drugs. Ten millimolar stock solutions of PI3K-isoform inhibitors were purchased from Selleckchem (Houston, TX). During experiments, the desired test concentrations were prepared according to the vendor's instructions, as needed. BYL716 (alpelisib)/A66, TGX221, AS252424, and idelalisib are inhibitors of PI3K- $\alpha$ (Juric et al., 2018; Park and Kim, 2018), $-\beta$ (Mao et al., 2017), $-\gamma$ (Jin et al., 2014), and $-\delta$ (Jin et al., 2016) subunits respectively, and BKM120 is an inhibitor of all four isoforms (Bashash et al., 2017). The concentrations used were 10-100 $\mathrm{nM}$, and the concentrations used to inhibit PI3K isoforms in cell assays are $\geq 1 \mu \mathrm{M}$ (Xu et al., 2013; Costa et al., 2015; Aragoneses-Fenoll et al., 2016). 
Statistical Analysis. Results are presented as mean \pm S.E.M. For comparisons of paired and unpaired groups, nonparametric Wilcoxon signed-rank sum and Mann-Whitney $U$ tests were used. For comparisons of three more groups, Kruskal-Wallis (K-W) one-way analysis of variance test was first performed to determine if there was a significant difference among means. If K-W test displayed a significant difference of $P<0.05$, then Dunnett's T3 post-hoc test was used in addition to examine the differences in mean values between two groups among multiple samples. Statistical analyses were carried out with SPSS software version 22 (IBM, Armonk, NY), OriginPro 8.5.1 (OriginLab), and Prism 7 (GraphPad Software, La Jolla, CA). A value of $P<0.05$ was considered statistically significant.

\section{Results}

Chronic Effects of Multiple Inhibitors of PI3K Subunits and Pan-PI3K on Adult Mouse Cardiac Action Potentials. We first determined the effects of a series of PI3K subunit inhibitors on action potentials (APs) from mouse ventricular myocytes drug-exposed for 5 hours. Before AP recordings, freshly isolated mouse ventricular myocytes were pretreated for 5 hours with individual inhibitors. As shown in Fig. 1, A-C, the two "pure" PI3K- $\alpha$ subunit inhibitors, BYL719 and A66, as well as the pan-PI3K inhibitor BKM120 caused AP abnormalities (varying from prolonged APs and triggered activity, described below). At a stimulation rate of $1 \mathrm{~Hz}$, this $\mathrm{AP}$ prolongation appeared more prominent during late repolarization with either $100 \mathrm{nM}$ BYL719 or $100 \mathrm{nM}$ A66, and action potential prolongation was evident at concentrations as low as $10 \mathrm{nM}$. Figure $1 \mathrm{D}$ summarizes $\mathrm{APD}_{90}$ by all inhibitors at $100 \mathrm{nM}$ concentration, and $10 \mathrm{nM}$ concentration of the $\alpha$-specific ones. Inhibition of PI3K- $\beta,-\gamma$, and $-\delta$ subunits did not alter $\mathrm{APD}_{90}$.

PI3K- $\alpha$ Inhibitors Are Arrhythmogenic. AP prolongation by the two selective PI3K- $\alpha$ subunit inhibitors was exaggerated when a slower stimulation rate $(0.1 \mathrm{~Hz})$ was used. Compared with non-drug-treated mouse ventricular myocytes (Fig. 2A), drug-treated cells displayed abnormal APs with triggered activity (Fig. 2, B and D). Further, these AP abnormalities were seen only at he initial recording after cell break-in, and resolved within minutes when the PI3K effector molecule PIP3 was included in the pipette solution (Fig. 2, C and E). Summary results are presented in Fig. $2 \mathrm{~F}$. In the absence of internal PIP3, abnormal APs included multiple forms (EADs, DADs, and triggered activity), whereas in the presence of PIP3, abnormal APs when seen were only in the form of single triggered upstrokes. Abnormal APs were also seen in 3/6 cells with the pan-PI3K inhibitor BKM120 but no abnormal APs were seen with the $\beta-, \gamma-$, and $\delta$-inhibitors.

PI3K- $\boldsymbol{\alpha}$ Inhibition Increases $\mathbf{I}_{\mathbf{N a L}}$. In untreated mouse ventricular myocytes, control $\mathrm{I}_{\mathrm{NaL}}$ at the end of a 200-millisecond pulse to $-30 \mathrm{mV}$ from a holding potential of $-120 \mathrm{mV}$ was small, $\sim 0.2 \%$ of the peak sodium current (Fig. 3A). In myocytes pretreated with either BYL719 or A66 for 5 hours, however, $\mathrm{I}_{\mathrm{NaL}}$ was increased 3- to 5-fold (Fig. 3, B-E) in a concentrationdependent fashion. Summary data are shown in Fig. 3F. To exclude the possibility that this result was attributable to loss of voltage control, we repeated the experiment with a lower extracellular sodium concentration $(50 \mathrm{mmol} / \mathrm{l}$, see Materials and Methods) and observed the same result (Supplemental Fig. 1). In separate experiments, we also demonstrated that all five PI3K subunit inhibitors did not affect peak sodium current (Supplemental Fig. 2).

To determine whether this increased $\mathrm{I}_{\mathrm{NaL}}$ is specific for the PI3K- $\alpha$ inhibition, we compared the effects of 48-hour exposures of the isoform-selective inhibitors and of BKM120 on $\mathrm{I}_{\mathrm{NaL}}$ in SCN5A-transfected CHO cells. As in untreated mouse ventricular myocytes, control $\mathrm{I}_{\mathrm{NaL}}$ level was $\sim 0.2 \%$ of the peak sodium current (Fig. 4A). BYL719 (1 $\mu \mathrm{M}, 48$ hours) still enhanced $\mathrm{I}_{\mathrm{NaL}}$ (Fig. 4B) and this effect was very similar to that seen in mouse myocytes (Fig. 3, B and C). The pan-PI3K inhibitor BKM120 also augmented $\mathrm{I}_{\mathrm{NaL}}$ (Fig. 4C). By comparison, the PI3K- $\beta,-\gamma$, and $-\delta$ inhibitors did not affect $\mathrm{I}_{\mathrm{NaL}}$ (Fig. 4, D-F). In addition, the action of BYL719 to increase $\mathrm{I}_{\mathrm{NaL}}$ under these conditions was reversed by including PIP3 in the pipette
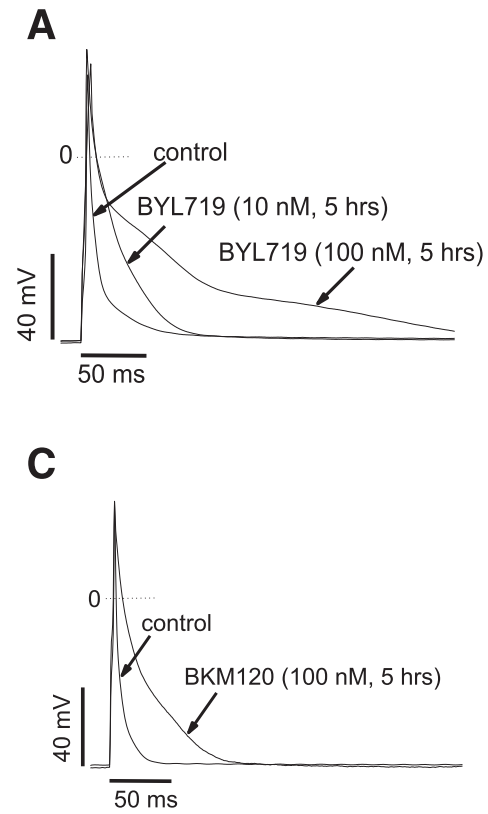
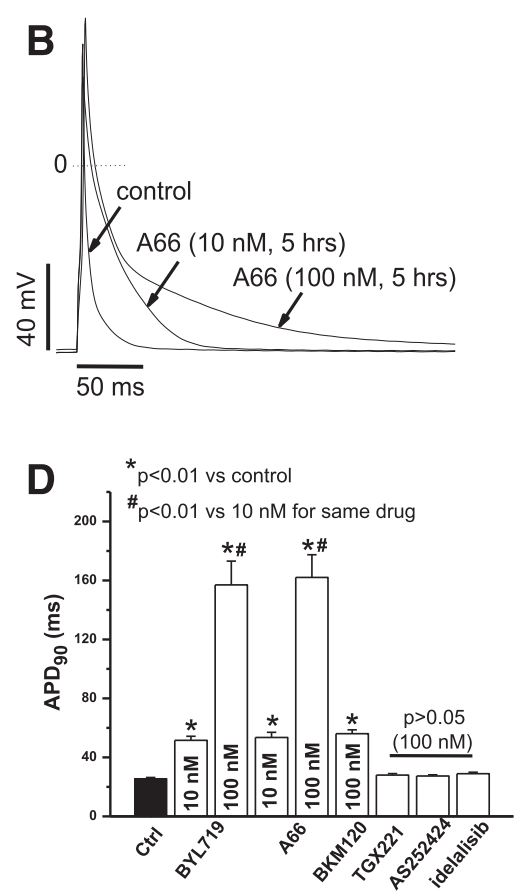

Fig. 1. Chronic PI3K- $\alpha$ and pan-PI3K inhibitors caused action potential prolongation and abnormal APs in adult mouse ventricular myocytes. (A) Chronic BYL719 (5 hours) prolonged APs in a concentration-dependent manner at a stimulation rate of $1 \mathrm{~Hz}$. (B) Chronic A66 (5 hours) prolonged APs in a concentration-dependent manner at a stimulation rate of $1 \mathrm{~Hz}$. (C) Chronic the pan-PI3K inhibitor BKM120 (5 hours) prolonged AP at a stimulation rate of $1 \mathrm{~Hz}$. (D) Summary of the effects on $\mathrm{APD}_{90}$ by all inhibitors at $1 \mathrm{~Hz}(n=5-8$ each $)$. 
A

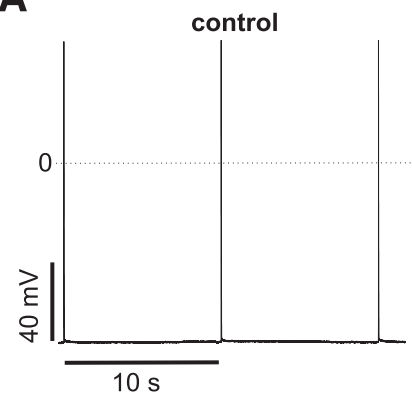

D

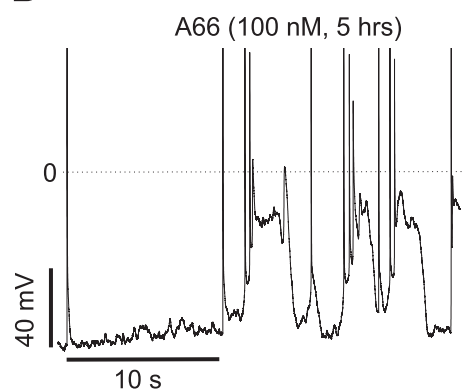

B

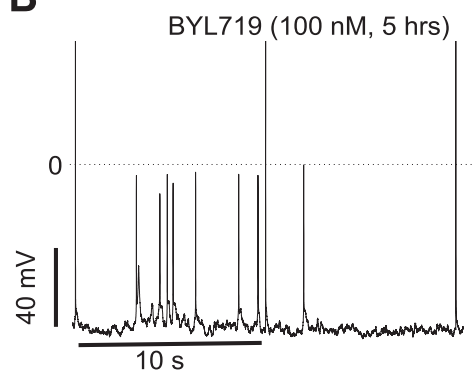

E

A66 (100 nM, 5 hrs $)+1 \mu \mathrm{M}[\mathrm{PIP} 3] \mathrm{i}$

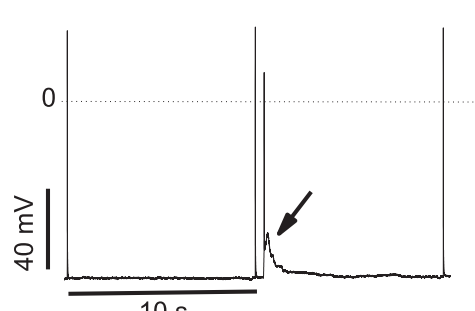

C

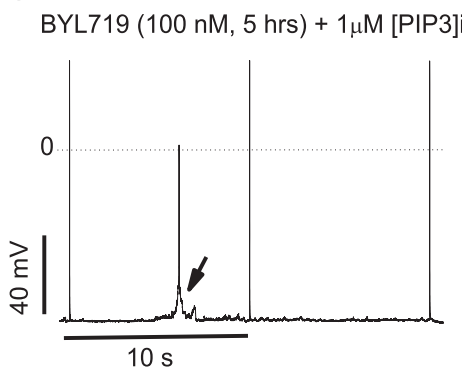

F

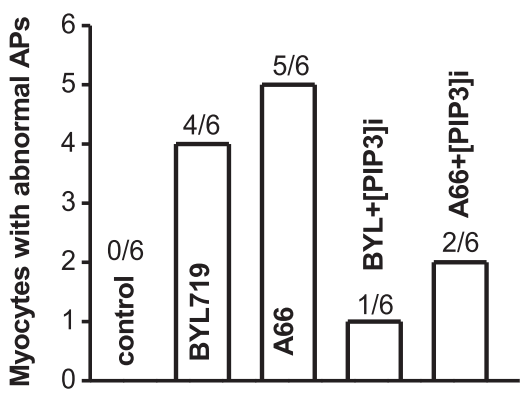

Fig. 2. Internally applied PIP3 antagonized action potential abnormalities by chronic PI3K- $\alpha$ inhibitors in adult mouse ventricular myocytes. (A) Control AP traces at a stimulation rate of $0.1 \mathrm{~Hz}$. (B) Chronic BYL719 induced triggered activity. (C) Inclusion of PIP3 in the internal pipette solution dramatically attenuated BYL719-induced abnormal action potentials (arrow). (D) Chronic A66 caused triggered activity. (E) Inclusion of PIP3 in the internal pipette solution dramatically attenuated A66-induced abnormal action potentials (arrow). (F) Summary of the numbers of myocytes with abnormal APs in each groups.

solution (Fig. 4G). Summary data for SCN5A-transfected CHO cells are presented in Fig. $4 \mathrm{H}$. The drug-induced increase in $\mathrm{I}_{\mathrm{NaL}}$ by chronic $\mathrm{A} 66$ ( $100 \mathrm{nM}$ ) was suppressed by ranolazine $(10 \mu \mathrm{M})$, a known blocker of $\mathrm{I}_{\mathrm{NaL}}$, which produced minimal effects on peak sodium current (Supplemental Fig. 3). All these data further support the hypothesis that $\mathrm{I}_{\mathrm{NaL}}$ contributes to the abnormal cardiac action potentials caused by PI3K- $\alpha$ inhibitors.

No Effect on $\mathbf{I}_{\mathrm{Kr}}$ or $\mathbf{I}_{\mathrm{TO}}$ of Acute or Chronic PI3K- $\alpha$ Inhibition. We also tested other potential mechanisms for AP prolongation. To date, the mostly widely accepted explanation for drug-induced QT prolongation has been $\mathrm{I}_{\mathrm{Kr}}$ inhibition. Therefore, we tested the acute (10 minutes) and chronic (48 hours) effects of 10 and $100 \mathrm{nM}$ of the two PI3K- $\alpha$ inhibitors (BYL719 and A66) on KCNH2-expressed current in CHO cells. As shown in Supplemental Fig. 4, the drugs had no effect on $\mathrm{I}_{\mathrm{Kr}}$ in these experiments. We also observed no effect of a high concentration $(3 \mu \mathrm{M})$ in cells expressing $K C N H 2$ and KCNE2 (Mirp1), a putative $\mathrm{I}_{\mathrm{Kr}}$ subunit (Supplemental Fig. 5).

In mouse myocytes, acute (10 minute) or chronic (5 hours) exposure to the two inhibitors had no effect on transient outward potassium current $\left(\mathrm{I}_{\mathrm{TO}}\right)$ in adult mouse ventricular myocytes (Supplemental Figs. 6 and 7). In addition, we found that including PIP3 in the intracellular (pipette) solution had no effect on $\mathrm{I}_{\mathrm{CaL}}, \mathrm{I}_{\mathrm{Kr}}$, or $\mathrm{I}_{\mathrm{Ks}}$ studied in CHO cells (Supplemental Fig. 8).

\section{Discussion}

The PI3K-PIP3 signaling pathway has been recognized as crucial in tumorigenesis and has therefore stimulated efforts for oncology drug development (Samuels et al., 2004; Yap et al., 2015; Massacesi et al., 2016). Although a role for PI3K in cardiac hypertrophy and contractile activity has been investigated in detail (Shioi et al., 2000; Dorn and Force, 2005; Rossello et al., 2017), the effects of the PI3K-PIP3 pathway in cardiac electrical activity and arrhythmogenesis have only recently begun to be defined. An initial study implicated $\mathrm{PI} 3 \mathrm{~K} \alpha$ in atrial fibrillation susceptibility in the mouse and human heart (Pretorius et al., 2009). More recently, a number of reports have implicated PI3K inhibition as a pathway to QT prolongation and subsequent arrhythmias (McMullen et al., 2014; Ballou et al., 2015; Ezeani and Elom, 2017). This is of great interest to the drug development community since druginduced QT prolongation is a major liability during drug development (Townsend, 2014). The usually accepted mechanism for drug-induced prolongation of cardiac action potentials and QT interval is inhibition of the rapidly activating potassium current $\mathrm{I}_{\mathrm{Kr}}$ conducted by the Kv11.1 channel, encoded by KCNH2, also known as HERG (Roden, 2008). However, acute exposure of canine cardiac myocytes to nilotinib (whose label carries a "black box" warning for QT prolongation) did not change action potentials (Lu et al., 2012), suggesting a mechanism beyond acute $\mathrm{I}_{\mathrm{Kr}}$ block. Chronic (hours) exposure to nilotinib reduced cell surface expression of a range of ion channels (including Kv11.1) and increased the amplitude of the persistent ("late") sodium current $\mathrm{I}_{\mathrm{NaL}}$, an effect known to prolong QT interval. These actions were reversed by including PIP3 in the patch pipette, providing strong evidence that the mechanism of the electrophysiologic effect of nilotinib was reduced PI3K activity, attributed to block of the receptor tyrosine kinase(s) that nilotinib targets. 
A

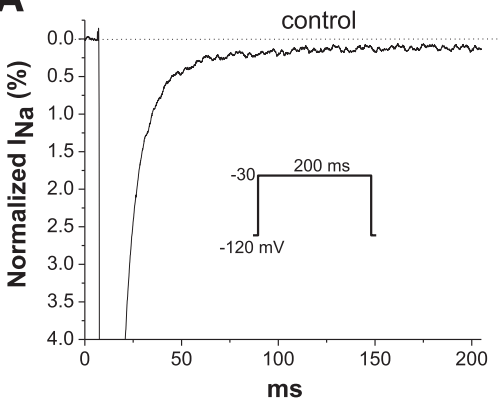

D

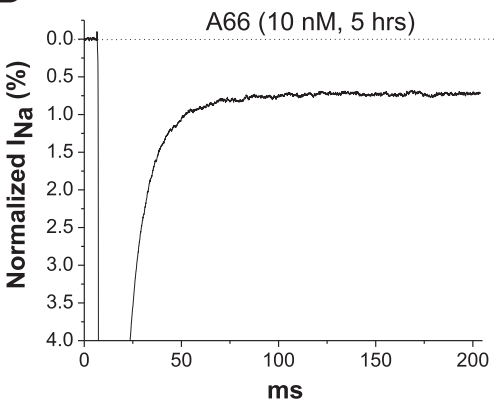

B

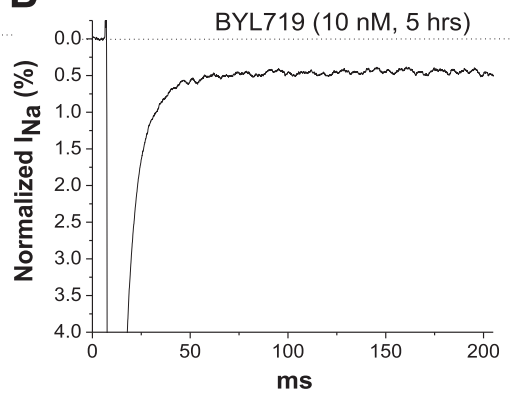

E

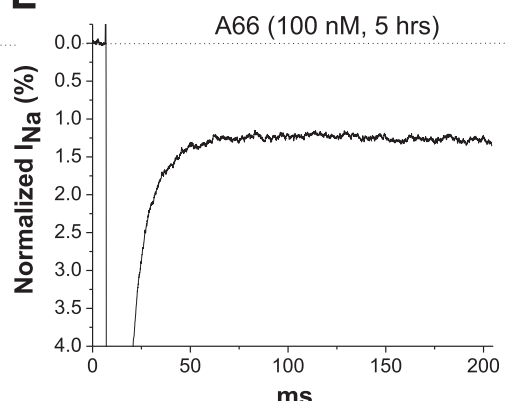

C

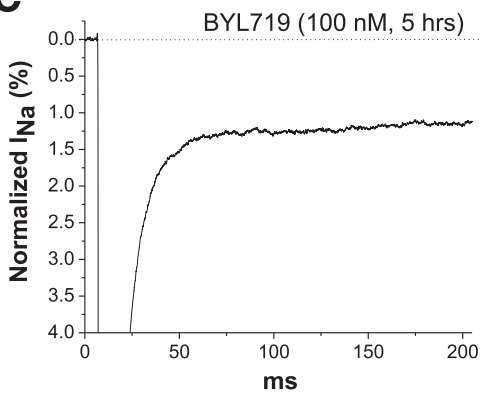

F

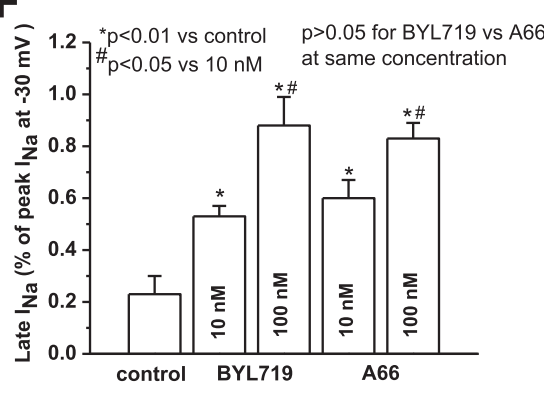

Fig. 3. Chronic PI3K- $\alpha$ inhibitors increased late $\mathrm{I}_{\mathrm{Na}}$ in adult mouse ventricular myocytes. (A) control current traces recorded with the protocol shown. (B and C) Effects of two concentrations of BYL719 (10 and $100 \mathrm{nM}$ ) on late $\mathrm{I}_{\mathrm{Na}}$ after 5-hour treatment. (D and E) Effects of two concentrations of A66 $\left(10\right.$ and $100 \mathrm{nM}$ ) on late $\mathrm{I}_{\mathrm{Na}}$ after 5-hour treatment. (F) Summary of the concentration-dependent increases in cardiac late $\mathrm{I}_{\mathrm{Na}}$ in mice by the two inhibitors ( $n=6-7$ each group). The two inhibitors increased late $\mathrm{I}_{\mathrm{NaL}}$ to the same extent.

Other work implicated the $\mathrm{I}_{\mathrm{NaL}}$ effect in prolonging repolarization in animal models of diabetes (Lu et al., 2013), a clinical setting associated with increased QT intervals, and we have shown that some but not all drugs known to block $\mathrm{I}_{\mathrm{Kr}}$ can prolong APs and generate arrhythmogenic afterdepolarizations through this pathway (Yang et al. 2014).
A

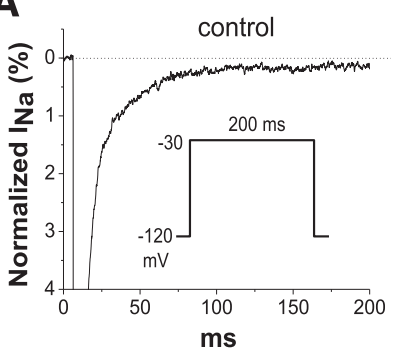

E

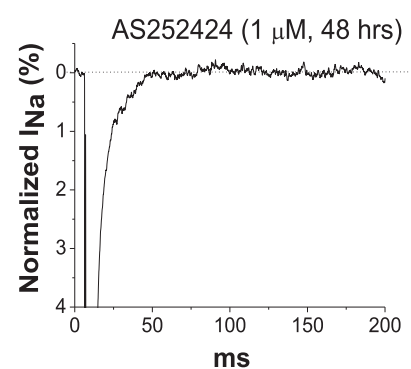

B

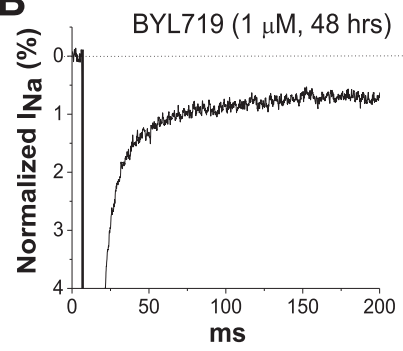

$\mathbf{F}$

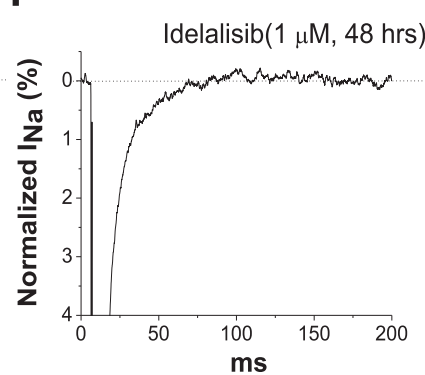

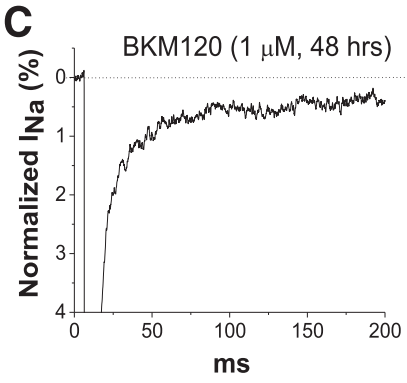

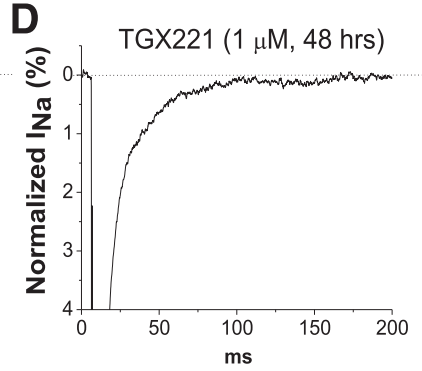

G

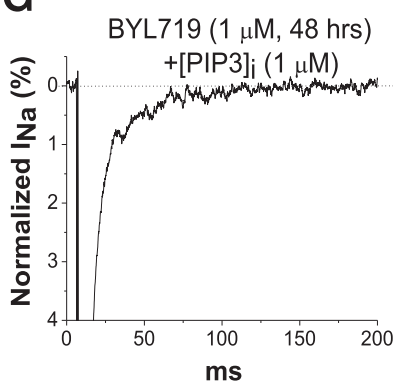

Fig. 4. Chronic PI3K- $\alpha$ and pan-PI3K inhibitors increased late $\mathrm{I}_{\mathrm{Na}}$ in SCN5A-transfected CHO cells. (A) Control $\mathrm{I}_{\mathrm{Na}}$ recorded with the protocol shown. (B) Current trace showing that chronic PI3K- $\alpha$ inhibitor BYL719 increased late $\mathrm{I}_{\mathrm{Na}}$. (C) Current traces showing that chronic pan-PI3K inhibitor BKM120 increased late $\mathrm{I}_{\mathrm{Na}}$. $(\mathrm{C}-\mathrm{F})$ Current traces showing that the inhibitors targeting PI3K- $\beta,-\gamma$, and $-\delta$ did not alter late $\mathrm{I}_{\mathrm{Na}}$. $(\mathrm{G})$ Current trace showing that internally adding PIP3 antagonized chronic BYL719-increased late $\mathrm{I}_{\mathrm{Na}}$. $(\mathrm{H})$ Summary $(n=6-8$ each group). 
To determine which PI3K isoform(s) drive altered cardiac electrophysiology and arrhythmogenesis, in the present study we examined the effects of multiple PI3K inhibitors on cardiac action potentials, late sodium current, and other major repolarizing outward potassium currents in isolated adult mouse cardiomyocytes (which lack $\mathrm{I}_{\mathrm{Kr}}$ and $\mathrm{I}_{\mathrm{Ks}}$ ) and in transfected CHO cells. The experimental results are summarized here: 1) Chronic (5 hours) exposure to PI3K- $\alpha$ subunit inhibitors (BYL716 and A66) and the pan-PI3K blocker BKM-120 caused AP prolongation and abnormalities (EADs, DADs, and triggered activity), and these effects were reversed when PIP3 was included in the pipette solution; 2) this chronic PI3K- $\alpha$ inhibitor exposure markedly increased late sodium current in mouse cardiomyocytes and in SCN5A-transfected cells, and the increased late current was abolished by ranolazine, a blocker of late sodium current; 3) chronic exposure to inhibitors of PI3K- $\beta,-\gamma$, and $-\delta$ did not alter mouse cardiac APs or late $\mathrm{I}_{\mathrm{Na}}$; and 4) acute and chronic exposures to selective PI3K- $\alpha$ inhibitors did not affect two major repolarizing potassium currents ( $\mathrm{I}_{\mathrm{TO}}$ and $H E R G$ ).

These data are compatible with the hypothesis that inhibition of PI3K- $\alpha$ subunit in the heart contributes to cardiac arrhythmogenesis by increasing late sodium current. The possibility that $\mathrm{PI} 3 \mathrm{~K} \alpha$ also affects other channels in the human heart, particularly over days or longer, cannot be excluded but the present data highlight the effects of the $\alpha$ isoform as primary in effecting the changes we reported here. The mechanism whereby PIP3 inhibits late sodium current has not been defined, but a direct interaction with the channel seems probable given the very rapid onset of action when PIP3 is included in the pipette solution. The mechanisms for the delay in onset of the effect with exposure to the kinase blockers has not been defined, but a time lag in driving down PIP3 concentrations is one possibility.

PI3K is the most frequently mutated signaling pathway in multiple tumor types, stimulating intense efforts to target PI3K or downstream kinase targets for the treatment of cancer (Samuels et al., 2004; Costa et al., 2017). Early efforts focused on specific PI3K inhibitor targeting $\delta$-(Gopal et al., 2014 ) and $\gamma$ - (Evans et al., 2016) isoforms, whose expression is generally restricted to hematopoietic cells. Idelalisib, a PI3K- $\delta$ inhibitor, was the first inhibitor approved for multiple hematologic malignancies. Current efforts have focused on panPI3K inhibitors or $\alpha$-specific inhibitors that might have broader efficacy (LoRusso, 2016). To date, mechanisms for drug-induced QT interval prolongation have been assumed to be acute and almost inevitably owing to drug targeting of $\mathrm{I}_{\mathrm{Kr}}$. As a result, regulatory agencies recommend that all drug candidates undergo in vitro testing for drug effects on $\mathrm{I}_{\mathrm{Kr}}$ in early development (Authier et al., 2010; Goineau et al., 2013; Vicente et al., 2016). The present data lead to a prediction that inhibitors of PI3K- $\alpha$ will prolong QT, but inhibitors of other isoforms may not (assuming no interaction with $\mathrm{I}_{\mathrm{Kr}}$ ), and that the QT prolongation would not be addressed appropriately during preclinical testing. To date, clinical trials have not reported systematically collected QT intervals in large numbers of drug-exposed subjects (Juric et al., 2017, 2018).

For new drug evaluations and drug safety pharmacology, our work reinforces the suggestion that drug effects should be investigated over time in both in vitro and in vivo biologic systems that include all of the components of normal and perhaps abnormal cardiac repolarization (Vicente et al., 2018).

\section{Acknowledgments}

The authors thank Wei Zhang, Lynn Hall, Laura Short, and Kaylen Kor for assistance with mouse management and myocyte isolation in this study.

\section{Authorship Contributions}

Participated in research design: Yang, Roden.

Conducted experiments: Yang.

Performed data analysis: Yang, Meoli.

Wrote or contributed to the writing of the manuscript: Yang, Meoli, Moslehi, Roden.

\section{References}

Abraham JM, Saliba WI, Vekstein C, Lawrence D, Bhargava M, Bassiouny M, Janiszewski D, Lindsay B, Militello M, Nissen SE, et al. (2015) Safety of oral dofetilide for rhythm control of atrial fibrillation and atrial flutter. Circ Arrhythm Electrophysiol 8:772-776.

Agarwal R, Carey M, Hennessy B, and Mills GB (2010) PI3K pathway-directed therapeutic strategies in cancer. Curr Opin Investig Drugs 11:615-628.

Antzelevitch C, Nesterenko V, Shryock JC, Rajamani S, Song Y, and Belardinelli L (2014) The role of late I Na in development of cardiac arrhythmias. Handb Exp Pharmacol 221:137-168.

Aragoneses-Fenoll L, Montes-Casado M, Ojeda G, Acosta YY, Herranz J, Martínez S, Blanco-Aparicio C, Criado G, Pastor J, Dianzani U, et al. (2016) ETP-46321, a dual $\mathrm{p} 110 \alpha / \delta$ class IA phosphoinositide 3-kinase inhibitor modulates T lymphocyte activation and collagen-induced arthritis. Biochem Pharmacol 106:56-69.

Authier S, Pugsley MK, Troncy E, and Curtis MJ (2010) Arrhythmogenic liability screening in cardiovascular safety pharmacology: commonality between nonclinical safety pharmacology and clinical thorough QT (TQT) studies. J Pharmacol Toxicol Methods 62:83-88.

Ballou LM, Lin RZ, and Cohen IS (2015) Control of cardiac repolarization by phosphoinositide 3-kinase signaling to ion channels. Circ Res 116:127-137.

Bashash D, Delshad M, Safaroghli-Azar A, Safa M, Momeny M, and Ghaffari SH (2017) Novel pan PI3K inhibitor-induced apoptosis in APL cells correlates with suppression of telomerase: an emerging mechanism of action of BKM120. Int $J$ Biochem Cell Biol 91 (Pt A):1-8.

Belardinelli L, Giles WR, Rajamani S, Karagueuzian HS, and Shryock JC (2015) Cardiac late $\mathrm{Na}^{+}$current: proarrhythmic effects, roles in long QT syndromes, and pathological relationship to CaMKII and oxidative stress. Heart Rhythm 12: 440-448.

Berenjeno IM and Vanhaesebroeck B (2009) PI3K regulatory subunits lose control in cancer [published correction appears in Cancer Cell (2010) 17:213]. Cancer Cell 16: 449-450.

Chen Y, Wang BC, and Xiao Y (2012) PI3K: a potential therapeutic target for cancer. J Cell Physiol 227:2818-2821.

Costa C, Ebi H, Martini M, Beausoleil SA, Faber AC, Jakubik CT, Huang A, Wang Y, Nishtala M, Hall B, et al. (2015) Measurement of PIP3 levels reveals an unexpected role for $\mathrm{p} 110 \beta$ in early adaptive responses to $\mathrm{p} 110 \alpha$-specific inhibitors in luminal breast cancer. Cancer Cell 27:97-108

Costa RLB, Han HS and Gradishar WJ (2018) Targeting the PI3K/AKT/mTOR pathway in triple-negative breast cancer: a review. Breast Cancer Res Treat DOI: 10.1007/s10549-018-4697-y [published ahead of print].

Courtney KD, Corcoran RB, and Engelman JA (2010) The PI3K pathway as drug target in human cancer. $J$ Clin Oncol 28:1075-1083.

Damilano F, Perino A, and Hirsch E (2010) PI3K kinase and scaffold functions in heart. Ann N Y Acad Sci 1188:39-45.

Dorn GW, II and Force T (2005) Protein kinase cascades in the regulation of cardiac hypertrophy. J Clin Invest 115:527-537.

Evans CA, Liu T, Lescarbeau A, Nair SJ, Grenier L, Pradeilles JA, Glenadel Q, Tibbitts T, Rowley AM, DiNitto JP, et al. (2016) Discovery of a selective phosphoinositide-3-kinase (PI3K)- $\gamma$ inhibitor (IPI-549) as an immuno-oncology clinical candidate. ACS Med Chem Lett 7:862-867.

Ezeani M and Elom S (2017) Necessity to evaluate PI3K/Akt signalling pathway in proarrhythmia. Open Heart 4:e000596.

Goineau S, Lemaire M, and Froget G (2013) Overview of safety pharmacology. Curr Protoc Pharmacol 63:Unit 10.11.

Gopal AK, Kahl BS, de Vos S, Wagner-Johnston ND, Schuster SJ, Jurczak WJ, Flinn IW, Flowers CR, Martin P, Viardot A, et al. (2014) PI3K $\delta$ inhibition by idelalisib in patients with relapsed indolent lymphoma. $N$ Engl J Med 370:1008-1018.

Jin F, Gao Y, Zhou H, Fang L, Li X, and Ramanathan S (2016) Population pharmacokinetic modeling of idelalisib, a novel PI3K $\delta$ inhibitor, in healthy subjects and patients with hematologic malignancies. Cancer Chemother Pharmacol 77:89-98. Jin M, Zhou Q, Lee E, Dan S, Duan HQ, and Kong D (2014) AS252424, a PI3K inhibitor, downregulates inflammatory responsiveness in mouse bone marrowderived mast cells. Inflammation 37:1254-1260.

Ju YK, Saint DA, and Gage PW (1994) Inactivation-resistant channels underlying the persistent sodium current in rat ventricular myocytes. Proc Biol Sci 256: 163-168.

Juric D, Krop I, Ramanathan RK, Wilson TR, Ware JA, Sanabria Bohorquez SM, Savage HM, Sampath D, Salphati L, Lin RS, et al. (2017) Phase I dose-escalation study of taselisib, an oral PI3K inhibitor, in patients with advanced solid tumors. Cancer Discov 7:704-715

Juric D, Rodon J, Tabernero J, Janku F, Burris HA, Schellens JHM, Middleton MR, Berlin J, Schuler M, Gil-Martin M, et al. (2018) Phosphatidylinositol 3 -kinase $\alpha$-selective inhibition with alpelisib (BYL719) in PIK3CA-altered 
solid tumors: results from the first-in-human study. $J$ Clin Oncol DOI: 10.1200/JCO.2017.72.7107 [published ahead of print].

LoRusso PM (2016) Inhibition of the PI3K/AKT/mTOR pathway in solid tumors. $J$ Clin Oncol 34:3803-3815.

Lowe JS, Stroud DM, Yang T, Hall L, Atack TC, and Roden DM (2012) Increased late sodium current contributes to long QT-related arrhythmia susceptibility in female mice. Cardiovasc Res 95:300-307.

Lu Z, Jiang YP, Wu CY, Ballou LM, Liu S, Carpenter ES, Rosen MR, Cohen IS, and Lin RZ (2013) Increased persistent sodium current due to decreased PI3K signaling contributes to QT prolongation in the diabetic heart. Diabetes 62: $4257-4265$.

Lu Z, Wu CY, Jiang YP, Ballou LM, Clausen C, Cohen IS, and Lin RZ (2012) Suppression of phosphoinositide 3-kinase signaling and alteration of multiple ion currents in drug-induced long QT syndrome. Sci Transl Med 4:131ra50.

Mao GH, Lu P, Wang YN, Tian CG, Huang XH, Feng ZG, Zhang JL, and Chang HY (2017) Role of PI3K p110 $\beta$ in the differentiation of human embryonic stem cells into islet-like cells. Biochem Biophys Res Commun 488:109-115.

Massacesi C, Di Tomaso E, Urban P, Germa C, Quadt C, Trandafir L, Aimone P, Fretault N, Dharan B, Tavorath R, et al. (2016) PI3K inhibitors as new cancer therapeutics: implications for clinical trial design. OncoTargets Ther 9:203-210.

Matsui T, Nagoshi T, and Rosenzweig A (2003) Akt and PI 3-kinase signaling in cardiomyocyte hypertrophy and survival. Cell Cycle 2:220-223.

McMullen JR, Boey EJ, Ooi JY, Seymour JF, Keating MJ, and Tam CS (2014) Ibrutinib increases the risk of atrial fibrillation, potentially through inhibition of cardiac PI3K-Akt signaling. Blood 124:3829-3830.

Park GB and Kim D (2018) Insulin-like growth factor-1 activates different catalytic subunits p110 of PI3K in a cell-type-dependent manner to induce lipogenesisdependent epithelial-mesenchymal transition through the regulation of ADAM10 and ADAM17. Mol Cell Biochem 439:199-211.

Pretorius L, Du XJ, Woodcock EA, Kiriazis H, Lin RC, Marasco S, Medcalf RL, Ming Z, Head GA, Tan JW, et al. (2009) Reduced phosphoinositide 3-kinase (p110alpha) activation increases the susceptibility to atrial fibrillation. Am J Pathol 175: 998-1009.

Qiu XS, Chauveau S, Anyukhovsky EP, Rahim T, Jiang YP, Harleton E, Feinmark SJ, Lin RZ, Coronel R, Janse MJ, et al. (2016) Increased late sodium current contributes to the electrophysiological effects of chronic, but not acute, dofetilide administration. Circ Arrhythm Electrophysiol 9:e003655.

Rigor DL, Bodyak N, Bae S, Choi JH, Zhang L, Ter-Ovanesyan D, He Z, McMullen JR, Shioi T, Izumo S, et al. (2009) Phosphoinositide 3-kinase Akt signaling pathway interacts with protein kinase Cbeta2 in the regulation of physiologic developmental hypertrophy and heart function. Am J Physiol Heart Circ Physiol 296 H566-H572.
Roden DM (2008) Clinical practice. Long-QT syndrome. N Engl J Med 358:169-176. Rossello X, Riquelme JA, He Z, Taferner S, Vanhaesebroeck B, Davidson SM, and Yellon DM (2017) The role of PI3K $\alpha$ isoform in cardioprotection. Basic Res Cardiol 112:66.

Saint DA, Ju YK, and Gage PW (1992) A persistent sodium current in rat ventricular myocytes. $J$ Physiol 453:219-231.

Samuels Y, Wang Z, Bardelli A, Silliman N, Ptak J, Szabo S, Yan H, Gazdar A, Powell SM, Riggins GJ, et al. (2004) High frequency of mutations of the PIK3CA gene in human cancers. Science 304:554.

Shioi T, Kang PM, Douglas PS, Hampe J, Yballe CM, Lawitts J, Cantley LC, and Izumo S (2000) The conserved phosphoinositide 3-kinase pathway determines heart size in mice. EMBO J 19:2537-2548.

Townsend C (2014) Is there a need to add another dimension (time) to the evaluation of the arrhythmogenic potential of new drug candidates in vitro? Circulation 130 219-220.

Vicente J, Stockbridge N, and Strauss DG (2016) Evolving regulatory paradigm for proarrhythmic risk assessment for new drugs. J Electrocardiol 49:837-842.

Vicente J, Zusterzeel R, Johannesen L, Mason J, Sager P, Patel V, Matta MK, Li Z Liu J, Garnett C, et al. (2018) Mechanistic model-informed proarrhythmic risk assessment of drugs: review of the "CiPA" Initiative and Design of a Prospective Clinical Validation Study. Clin Pharmacol Ther 103:54-66.

Wu L, Ma J, Li H, Wang C, Grandi E, Zhang P, Luo A, Bers DM, Shryock JC, and Belardinelli L (2011) Late sodium current contributes to the reverse ratedependent effect of $\mathrm{IKr}$ inhibition on ventricular repolarization. Circulation 123: $1713-1720$.

Xu H, Li X, Liu D, Li J, Zhang X, Chen X, Hou S, Peng L, Xu C, Liu W, et al. (2013) Follicular T-helper cell recruitment governed by bystander B cells and ICOSdriven motility. Nature 496:523-527.

Yang T, Atack TC, Stroud DM, Zhang W, Hall L, and Roden DM (2012) Blocking Scn10a channels in heart reduces late sodium current and is antiarrhythmic. Circ Res 111:322-332.

Yang T, Chun YW, Stroud DM, Mosley JD, Knollmann BC, Hong C, and Roden DM (2014) Screening for acute IKr block is insufficient to detect torsades de pointes liability: role of late sodium current. Circulation 130:224-234.

Yap TA, Bjerke L, Clarke PA, and Workman P (2015) Drugging PI3K in cancer: refining targets and therapeutic strategies. Curr Opin Pharmacol 23:98-107.

Address correspondence to: Dr. Dan M. Roden, 1285 Light Hall, MRB-4, 2215B Garland Avenue, Vanderbilt University School of Medicine, Nashville, TN 37232. E-mail: dan.roden@vanderbilt.edu 